\title{
DIVERSIDADE E IN/EXCLUSÃO: VOZES E SILÊNCIOS NA FORMAÇÃO DO/A PEDAGOGO/A
}

\author{
COSTA, Joacir Marques da* \\ CORTE, Marilene Gabriel Dalla** \\ SILVA, Luciana Guilhermano***
}

\begin{abstract}
RESUMO
Este trabalho de pesquisa tem como temática central a diversidade nos processos formativos no curso de Pedagogia, pois tanto escola como universidade são produzidas/produtoras de um contexto plural, multicultural e de múltiplas identidades. Nesse sentido, problematiza-se "como é produzido o discurso de diversidade, considerando o processo de formação do/a pedagogo/a na dimensão de educação para todos/as?". Logo, como objetivo geral optou-se por compreender a produção discursiva acerca da diversidade, considerando os processos formativos do/a pedagogo/a na dimensão de educação para todos/as. Os aportes teórico-metodológicos desenharam-se mediante uma pesquisa de abordagem qualitativa, do tipo estudo de caso, utilizando-se, para a produção de dados, da análise documental do projeto pedagógico de um curso de Pedagogia (noturno) de uma universidade pública do Rio Grande do Sul. Conclui-se que dialogar e problematizar sobre diversidade é um processo formativo que transcende a formação formal em um curso de licenciatura; como participantes dos diversos processos educativos, é necessário estabelecer relações reflexivas entre os saberes disciplinares e os saberes da prática educativa, (des)construindo conceitos, ao olhar o interior de nossas ações, as quais resultam em mudanças nas práticas pedagógicas essenciais para a reflexão da diversidade cultural e dos mecanismos de in/exclusão presentes na sociedade contemporânea.
\end{abstract}

PALAVRAS-CHAVE: Diversidade. In/exclusão. Pedagogia. Formação. Projeto Político-pedagógico.

\footnotetext{
* Doutor em Educação. Professor Adjunto na Universidade Federal do Pampa. Pesquisador do Grupo ELOS/CNPq.

* * Doutora em Educação. Professora Adjunta do Departamento de Administração Escolar, do Centro de Educação da Universidade Federal de Santa Maria. Líder do Grupo de Pesquisa GESTAR/CNPq/UFSM.

*** Graduada em Pedagogia Licenciatura Plena pela Universidade Federal de Santa Maria. Participante nos Grupos de Pesquisa GESTAR/CNPq/UFSM e ELOS/CNPq/UFSM.
} 


\title{
DIVERSITY AND IN/EXCLUSION: \\ VOICES AND SILENCES IN THE FORMATION OF THE EDUCATOR
}

\author{
COSTA, Joacir Marques da* \\ CORTE, Marilene Gabriel Dalla** \\ SILVA, Luciana Guilhermano***
}

\begin{abstract}
This research has as main theme the diversity in the formative processes in the Pedagogy course, because both school and university are produced / producers of a plural, multicultural and multiple identities. Thus, the following question was problematized: "how the diversity of speech is produced, considering the educator formation process in the education dimension for everyone?" However, as main objective was decided to understand the discursive production about diversity, considering the formative processes of the educator in the dimension of education for all. The theoretical and methodological contributions were drawn by qualitative research and case study, for the data production, was used the analysis of the pedagogy course program (in the evening) from a public University in Rio Grande do Sul. Thus, it's concluded that to dialogue and discuss about diversity is a training process, which transcends formal education in an undergraduate course; as participants from the different educational processes, it is necessary the reflexive relations between disciplinary knowledge and the knowledge of educational practice, (de) constructing concepts, to look inside of our actions, which result in changes in the essential teaching practices to reflect the cultural diversity and in mechanisms / exclusion present in contemporary society.
\end{abstract}

KEYWORDS: diversity. In/exclusion. Pedagogy. Formation. Pedagogical-political project

\footnotetext{
* Doutor em Educação. Professor Adjunto na Universidade Federal do Pampa. Pesquisador do Grupo ELOS/CNPq.

* * Doutora em Educação. Professora Adjunta do Departamento de Administração Escolar, do Centro de Educação da Universidade Federal de Santa Maria. Líder do Grupo de Pesquisa GESTAR/CNPq/UFSM.

*** Graduada em Pedagogia Licenciatura Plena pela Universidade Federal de Santa Maria. Participante nos Grupos de Pesquisa GESTAR/CNPq/UFSM e ELOS/CNPq/UFSM.
} 


\section{PRIMEIRAS PALAVRAS}

A escola é responsável por exercer papel complementar ao da família, na tarefa de possibilitar um amplo diálogo sobre ética e moralidade, visto que esse espaço é território de encontro, confronto e negociação de diferenças. Como a Pedagogia é um campo teóricoinvestigativo a partir e sobre as práticas educativas, no centro das atividades escolares o debate ético e político oportunizam que essas diferenças sejam convertidas em respeito mútuo, tolerância, diálogo e solidariedade, frente à cultura da diversidade existente na sociedade contemporânea. No entanto, “[...] quando a escola se exime desse papel, as diferenças interpessoais e de grupos passam a representar constante fonte de conflitos, contribuindo para o fechamento e o predomínio da cultura do preconceito sobre a cultura da diversidade" (SANTANA; OLIVEIRA, 2012, p. 73).

Sendo a diversidade foco dessa problematização, esta produção é resultante de indagações subjacentes aos processos formativos no curso de Pedagogia, entendidos pela interlocução de atividades de ensino, pesquisa e extensão. Sublinha-se que esses processos produzem conhecimentos tanto teóricos como práticos, bem como sentidos para compreender que a universidade e os cursos de formação de professores/as não podem ser reflexos de valores, crenças e moralidades que marginalizam sujeitos da sociedade, sendo, pois, espaços de atitude crítico-reflexiva sobre modos de in/exclusão social. Nessa perspectiva, a universidade e a escola poderão ser vistas com potencial de interdependência nas relações e ações político-pedagógicas, capazes de colaborar na construção de uma sociedade mais democrática e igualitária, na perspectiva de transformações tanto pessoais e coletivas, como institucionais.

Num contexto plural e multicultural em que se encontram as instituições, torna-se significativo o projeto político-pedagógico (PPP), elemento norteador dos princípios, das prioridades, ações administrativas e pedagógicas institucionais; necessário para definir as metas que se pretende para o desenvolvimento e a aprendizagem dos/as alunos/as. No PPP se caracteriza o processo de mudança e de transformação necessária no âmbito educativo, 
estabelecendo propostas para organizar, sistematizar e significar as atividades desenvolvidas na escola. Padilha (2003) afirma que nesse processo de construção participativa com a comunidade escolar, os indivíduos confirmam seus saberes, dão sentido aos seus sonhos e utopias, reafirmam suas identidades e estabelecem novas relações de convivência, evidenciando que a ação humana no coletivo escolar é transformadora.

Com isso, questionamos acerca dos processos formativos dos/as pedagogos/as em uma Instituição de Ensino Superior (IES) e da relevância das discussões acerca da temática diversidade no transcorrer desses processos, já que tanto escola como universidade são produzidas/produtoras de um contexto plural, multicultural e de múltiplas identidades. Por isso, o questionamento inicial deste trabalho de pesquisa está centrado na seguinte problemática: Como é produzido o discurso de diversidade, considerando o processo de formação do/a pedagogo/a na dimensão de educação para todos/as? Para tanto, objetiva-se, de maneira geral, compreender a produção discursiva acerca da diversidade, considerando os processos formativos do/a pedagogo/a na dimensão de educação para todos/as. Tal compreensão concebe a forma discursiva acerca da noção de diversidade como forma material, sendo, pois, a forma linguístico-histórica, nem empírica, nem abstrata, mas a própria língua no processo histórico-social, colocando o sujeito e os sentidos como partes desse processo (ORLANDI, 2012). Com isso, as formações discursivas configuram-se como as diferentes formulações de enunciados que se reúnem em pontos do dizer, em regiões historicamente determinadas de relações de força e de sentidos (ORLANDI, 2007).

\subsection{Elementos Teórico-Metodológicos}

Os pressupostos teórico-metodológicos desta pesquisa estão ancorados na abordagem qualitativa, do tipo estudo de caso (YIN, 2005). Entende-se que a abordagem qualitativa de pesquisa se constrói em um modo aberto e flexível, focalizando a realidade de forma complexa e contextualizada, de maneira que o/a investigador/a "[...] procurará se manter constantemente atento a novos elementos que podem emergir como importantes durante o estudo" (LÜDKE; ANDRÉ, 1986, p. 18).

A produção da pesquisa do tipo estudo de caso trata-se de um estudo de natureza empírica que investiga um determinado fenômeno, dentro de um contexto real de vida. Nesse 
tipo de pesquisa há uma intervenção direta do/a pesquisador/a na pesquisa, percebendo os significados que vão sendo obtidos e considerando os mais relevantes dentro do contexto sociocultural em que ocorrem os fenômenos. Segundo Yin (2005), o estudo de caso representa-se como uma investigação empírica e compreende um método abrangente, abarcando a lógica do planejamento, da coleta e da análise de dados.

Tendo como lócus de pesquisa a Universidade Federal de Santa Maria (UFSM), especificamente o curso de Pedagogia Licenciatura Plena (noturno), a produção de dados realizou-se mediante o estudo de bibliografias que pudessem dialogar com as temáticas do trabalho e, sobretudo, a análise documental do PPP do curso. Lima (2004, p. 112) afirma que a análise documental é “[...] um recurso metodológico indispensável quando desejamos explorar temas que recuperam dimensões históricas da realidade”. Logo, partiu-se de aportes teóricos e teórico-metodológicos considerados indispensáveis para uma significativa análise da realidade e dos documentos e, com isso, foram abarcados os objetivos da pesquisa.

Ademais, durante a escrita deste texto são utilizadas palavras que têm só uma forma para os dois gêneros (masculino e feminino) como a palavra docente (a/o docente), e palavras no feminino e no masculino, como o pedagogo e a pedagoga, evitando a aplicação sexista da linguagem - a qual acredita que ao nomear um grupo misto de pessoas no masculino está nomeando também as mulheres.

Segundo o Manual para o uso não sexista da linguagem: o que bem se diz bem se entende, “[...] as palavras não podem significar algo diferente do que nomeiam. O conjunto da humanidade está formado por mulheres e homens, mas em nenhum caso a palavra 'homem' representa a mulher" (RIO GRANDE DO SUL, 2014, p. 29). Portanto, para torná-la representada e visível na sociedade é preciso nomeá-la, possibilitar o respeito pela diversidade.

O grupo de profissionais que atuam no âmbito escolar é formado por professores e professoras, então por que referenciar somente professores como sendo neutro, se sabemos que tal palavra trata-se de um substantivo masculino no plural? O posicionamento assumido neste texto está pautado na utilização da linguagem para promover uma cultura inclusiva e não-sexista, de promoção a igualdade de gênero, a fim de potencializar uma mudança de 
mentalidade. Desse modo, compreende-se que o uso da linguagem não-sexista ao abordar "pedagogo/a" presente no título deste trabalho demarca a presença de uma não hierarquia de gênero. Ou seja, mulheres e homens valorizados igualmente na diversidade.

\section{IN/EXCLUSÃO EM INTERFACE COM A DIVERSIDADE NA ESCOLA E NA UNIVERSIDADE}

Discutir a respeito da inclusão social é dar voz para as diversas formas de manifestação da exclusão, é oportunizar a promoção de novas culturas, novas sociabilidades, sendo uma nova questão social no âmbito econômico, político e social (SILVA, 2012). No entanto, tal questão prevê um entendimento sobre os conceitos que permeiam as palavras exclusão e inclusão.

Exclusão e inclusão podem, sob um ponto de vista, designar três ideias diferentes: grande número de pessoas que vivem na miséria; limites de fronteira entre o dentro e o fora; e as discriminações negativas envolvendo etnia, gênero, religião, necessidades especiais, educação, entre outros fatores (LOPES; FABRIS, 2013). Entretanto, tais termos sofreram deslocamentos de uso, da Idade Média até o século XIX.

Segundo Lopes e Fabris (2013), Michel Foucault denominou os movimentos de exclusão, reclusão e inclusão de indivíduos a corrigir, sendo

[o]s indesejados, os doentes, os perigosos, os desviantes, os deficientes, os loucos ou qualquer um que antes era denominado de anormal ou incorrigível, passaram a ser tratados como alguém a recuperar. Dessa forma, no século XIX, tais sujeitos deixaram de ser "os excluídos" (no sentido de mortos para o social), ou de ser isolados em confinamentos particulares. Sem ser possível observar rupturas históricas entre as práticas de exclusão e as práticas de reclusão, a inclusão se estabeleceu como uma forma econômica de cuidado e educação da população (LOPES; FABRIS, 2013, p. 61).

Nessa lógica, os termos exclusão, reclusão e inclusão tornaram-se “[...] invenções derivadas não de rupturas, mas de mudanças de ênfases e de deslocamentos, é possível reconhecer nas práticas do presente, heranças do século XVIII em diante" (LOPES; FABRIS, 2013, p. 62).

Historicamente, o conceito de exclusão tinha por significado apontar aqueles que eram afastados e/ou retirados do convívio social através de confinamentos, restrição de acesso, 
entre outras práticas sociais. Essas pessoas não possuíam direitos, estavam isoladas na sociedade. Entretanto, do conceito de exclusão derivou-se o conceito de desfiliação, relacionado à vulnerabilidade social. Nesse caso, "[...] o sujeito não vive a situação de ausência completa de vínculo (como no caso do excluído), pois não está fora da sociedade, mas afastado de sua força centrípeta" (LOPES; FABRIS, 2013, p. 63). Nessa realidade podem ser consideradas as pessoas desempregadas por longo tempo, as pessoas analfabetas e/ou que possuem pouca escolaridade, entre outros casos; situação que acaba afastando as pessoas dos processos econômicos da sociedade, que envolvem a produção e o consumo.

Segundo Lopes e Fabris (2013), Robert Castel (1997) afirma que as pessoas estão classificadas em dois eixos: o do trabalho e o relacional, e tais eixos quando discutidos na atualidade mobilizam os conceitos integração e inclusão, “[...] pois ambos dão conta de uma dimensão física de estar no mesmo espaço que o outro (integração), e de uma dimensão vivida na relação com o outro (inclusão)" (LOPES; FABRIS, 2013, p. 64).

O conceito de inclusão, assim como a palavra exclusão, sofreu/sofre ressignificações. Stainback e Stainback (1999) afirmam que o termo inclusão teve sua origem na palavra inglesa 'full inclusion', o qual trouxe um novo paradigma apoiado no princípio da "educação para todos". A educação para todos prevê acesso à educação e à vida social - princípios fundamentais para o indivíduo se manter nos processos econômicos - , ter ou não ter acesso a eles gera um caráter oposicional-binário entre inclusão e exclusão.

Nos anos 1960-1970, a relação entre o funcionamento do âmbito escolar e as desigualdades sociais produzia desigualdades nas aprendizagens escolares. No entanto, por volta dos anos 1980, a escola voltou a ter sua importância social reconhecida. Se por um lado a escola era culpada pela discriminação e pela "[...] exclusão de alunos provenientes das camadas populares, por outro, ela poderia ser um meio indispensável de elevação cultural, de formação para a cidadania e de desenvolvimento de conhecimento e capacidades para enfrentamento das condições adversas de vida" (LIBÂNEO, 2004, p. 29). Dessa maneira, a educação passou a ser um campo de disputa o qual propicia, ou não, acesso aos processos econômicos e melhoria nas condições de vida da população. 
Segundo Lopes e Fabris (2013), outra possibilidade para o termo inclusão é pela perspectiva de integração, ou seja, entende-se por inclusão estar junto no mesmo espaço físico, atrelado à noção de normação/correção daquilo que é anormal ou incorrigível nas pessoas.

A norma disciplinar é constituída a partir de um normal universal. Isso significa que primeiro se define a norma e depois se identificam os sujeitos, sempre de forma dicotômica ou polarizada, como normais e anormais, incluídos e excluídos, sadios e doentes, deficientes e não deficientes, aprendentes e não aprendentes, ricos e pobres, brancos e negros, etc. Por normalização marcamos um processo inverso ao de normação. A normalização parte do apontamento do normal e do anormal dado a partir das diferentes curvas de normalidade, para determinar a norma (LOPES; FABRIS, 2013, p. 42).

Nesse impasse, a diferença precisa ser reduzida ao mesmo, tornando um oposto ao outro, além de semelhante à diversidade. A palavra integração apareceu nomeada oficialmente na história das políticas educacionais brasileiras na década de 1990. Durante o primeiro mandato do presidente Fernando Henrique Cardoso (FHC), de 1995 a 1998, “[...] integração era a palavra utilizada para caracterizar as iniciativas de colocar aqueles alunos que não estavam nas escolas regulares para dentro de tais escolas" (LOPES; FABRIS, 2013, p. 69). Portanto, buscou-se reparar uma dívida com tais alunos/as que se encontravam à margem da rede/espaço social e educacional.

Com a ampliação do conceito de integração nos programas governamentais, a noção de normalização passou a transitar nesse território, sob a ótica restrita de correção dos indivíduos, até que a palavra inclusão passou a ser novamente problematizada nas políticas educacionais do país, sendo utilizada nos documentos legais somente no segundo mandato do presidente FHC (1999-2002).

O conceito de inclusão está fortemente presente no discurso internacional e a noção de normalização antes vista como maneira de corrigir os diferentes/anormais passa a ser compreendida como investimento intenso do Estado para o controle e a regulação da população. Lunardi (2001, p. 03) afirma que a "[...] normalidade é o local onde a possibilidade de governar os corpos se materializa, pois, considera os sujeitos a partir da normalização, possibilitando o controle, e exercendo o bio-poder, o poder sobre a vida". 
Assim, nas escolas as práticas corretivas-disciplinares ficam em segundo plano, e a inclusão recebe, de imediato, o investimento do Estado e das teorias educacionais presentes nos cenários pedagógicos. Portanto, aqueles que eram ignorados pelo Estado, que viviam em reclusão, passam a viver em uma reclusão temporária para a reeducação e inclusão social.

Se formos pensar na palavra exclusão como aqueles afastados e/ou retirados do convívio social, podemos concluir que vivemos em uma sociedade de inclusão. No entanto, não existe alguém que esteja completamente incluído ou excluído, “[...] o que há são jogos de poder em que, dependendo da situação, da localização e da representação alguns são enquadrados e outros não" (LUNARDI, 2001, p. 01).

Para Lopes e Fabris (2013, p. 74):

[...] cada vez é mais difícil apontar o excluído, embora seja fácil falar de cidadãos miseráveis, desempregados por longa data, cidadãos sem-teto, cidadãos sem-terra, cidadãos com deficiência, entre outros cidadãos historicamente discriminados por questões de gênero e sexualidade, de raçaetnia, de deficiência, de doença, etc. Então, as políticas e as ações biopolíticas teriam feito desaparecer os excluídos? Se nos orientarmos por usos muito restritos para a palavra exclusão, como aquele que tem a sua existência ignorada pelo Estado, talvez sejam estatisticamente poucos os casos de excluídos no Brasil.

Assim, se utilizarmos a palavra exclusão para enfatizar os direitos dos indivíduos, muitos casos de inclusão excludente ou in/exclusão aparecerão. Dessa maneira, o termo in/exclusão passa a abranger os diversos tipos humanos que vivem sob inúmeras condições, que carregam consigo histórias negativas de discriminação; surge para mostrar que boa parte da população ainda sofre com práticas sociais de inclusão excludente, ou seja, pessoas de grupos discriminados são impedidos e/ou limitados a participar das mesmas práticas, ações, espaços e políticas dos grupos que integram. Lunardi (2001, p. 01) sinaliza que "[...] atualmente, a problemática da inclusão/exclusão vem atingindo a todos nas suas mais diversas formas, ou seja, todos podem ser excluídos de alguma situação e incluídos em outra”. Logo, as práticas de in/exclusão, a partir das noções de poder/saber, elementos centrais na produção de discursos e práticas pedagógicas, são entendidas como duas faces da mesma moeda (LUNARDI, 2001). 
É possível afirmar que os in/excluídos estão integrados, pois fazem parte de um mesmo espaço, mas nas relações interpessoais, sofrem discriminações. A ausência do pertencimento coletivo, resultante da situação vulnerável de alguns grupos, acaba gerando consequências, tornando as pessoas suscetíveis a uma individualidade negativa; marcada pela falta de suportes relacionais, culturais e econômicos “[...] que lhe[s] sirvam de apoio e condições de possibilidades para se tornarem sujeitos e protagonistas, com capacidade de desenvolver estratégias pessoais, autonomia, independência e liberdade de escolha na condução de sua vida” (SILVA, 2012, p. 268). Com isso, “[...] a palavra inclusão passa a abarcar as relações interpessoais, além de estar junto (entendimento como condição mínima necessária mas não suficiente para as ações de inclusão)" (LOPES; FABRIS, 2013, p. 70).

Com investimento do Estado na educação para se trabalhar a inclusão, ou seja, a subjetividade inclusiva, os indivíduos serão capazes de se ocupar um com o outro, na militância das causas ambientais, animais e humanas; sem romper com a lógica do capitalismo, visto a necessidade de permanência nos processos econômicos, através da supervalorização da inclusão no mercado de trabalho (LOPES; FABRIS, 2013). Nessa permanência, a liberdade e o individualismo (autonomia individual) são apontados como estratégias para fortalecer/capacitar o sujeito a progredir, alcançar seus sonhos e perspectivas de vida, na parceria com o Estado e o mercado de trabalho.

Contudo, conforme Silva (2012), a inclusão social atinge um conjunto de ações sociais, econômicas e políticas. A inserção social é viabilizada por meio do acesso à educação de qualidade, oportunidade de trabalho e acesso a políticas públicas emancipatórias. Tais medidas tornam possível a igualdade de direitos e oportunidades, o acesso a bens e serviços, a interação social e, consequentemente, a qualidade de vida da população.

Nisso, o universo cultural da escola, além de ser um espaço onde se ensinam conhecimentos, atitudes e valores, é um importante espaço institucional na construção de quem somos, pois tem o poder de articular e/ou contestar as formas de ver e imaginar a sociedade (BORGES; MEYER, 2008). Para pensarmos o tema da diversidade cultural na educação escolar, é necessária a reflexão constante sobre crenças, valores e posturas diante de conhecimentos pré-estabelecidos pela sociedade. "Não é um tema com o qual possamos nos desfazer em racionalidades, ou nelas disfarçar, como se fossem exteriores em tal medida que consideremos estar tratando apenas dos outros" (AMORIN, 2010, p. 04), requer um 
autoconhecimento subjetivo para romper e resistir às imaginárias e fantasiosas configurações do mundo.

Segundo Gadotti (2000), a escola não educava para a cidadania, a estrutura de poder do Brasil era mantida pela classe dominante que dificultava a consciência crítica da população, infelizmente, essa estrutura político-social e econômica ainda é dominante. "Mas, a mesma sociedade que cria essa estrutura cria também a sua reação. A contradição social existe. Por isso, encontramos motivos para ser otimistas" (GADOTTI, 2000, p. 11). Para superar essa hegemonia relativa às classes dominantes, Almeida e Tello (2015) preveem o desenvolvimento de uma consciência crítica por meio de teoria e reflexão-ação, que resulte uma "nova cultura" na qual as classes trabalhadoras possam sair da submissão para chegar a uma nova sociedade, construída com a participação de todos/as.

A educação passa a ser considerada como eixo de desconstrução das desigualdades sociais em prol da construção de uma realidade, anteriormente, marginalizada. "É o caso do direito à diferença. Certas diferenças, antes discriminatórias pela hierarquização social, se tornam objeto de reparação histórica para aqueles que sofreram segregações ou se tornaram vítimas da escravatura" (CURY, 2015, p. 11). Assim, os conceitos de igualdade, equidade, respeito ativo, diálogo e solidariedade, correspondentes à cidadania civil e intercultural, passam a ser essenciais para o princípio de justiça social.

Segundo Amorim (2010), uma possibilidade para cultivar a construção da igualdade e a liberdade seria por meio do diálogo e da interação entre os diferentes, em um ambiente de cooperação e valores humanitários comuns, vinculados a singularidades, que possibilitasse o desprendimento de ideias na busca do 'status universal', apropriado para todas as pessoas.

\subsection{Universidade e Formação do/a pedagogo/a}

A Educação Superior está prevista na Constituição Federal de 1988 (BRASIL, 1988) e suas finalidades, estrutura e funcionamento estão explicitadas na Lei de Diretrizes e Bases da Educação Nacional - LDBEN (BRASIL, 1996). Quanto à finalidade da Educação Superior, Art. 43 consta, de maneira ampla, que é esperado que os/as formandos/as: desenvolvam o 
pensamento crítico perante os processos sociais e aos problemas existentes no mundo e em particular os nacionais e regionais; participem e colaborem no desenvolvimento da sociedade em uma relação de reciprocidade; considerem a interculturalidade como construção social; e permaneçam se aperfeiçoando cultural e profissionalmente por meio da difusão das conquistas e benefícios para a criação cultural e da pesquisa científica e tecnológica geradas na instituição.

A Pedagogia, foco deste trabalho, é um campo de conhecimento que possui objeto, problemáticas e métodos próprios de investigação. O campo da Pedagogia ocupa-se da educação intencional, é uma área científica que tem a educação como objeto de estudo, e seu objetivo "[...] se configura na relação entre os elementos da prática educativa: o sujeito que se educa, o educador, o saber e os contextos em que ocorre" (LIBÂNEO, 2002, p. 38). Estando envolvida no estudo sistemático das práticas educativas que se realizam em sociedade como processos fundamentais da condição humana, se debruça sobre a investigação da natureza, das finalidades e dos processos necessários às práticas educativas, com o objetivo de realizar esses processos nos vários contextos da sociedade em que essas práticas ocorrem.

É por meio da educação que ocorrem os processos de comunicação e interação, pelos membros da sociedade, resultando em saberes, habilidades, atitudes e valores existentes no meio cultural. Todo ato educativo tem seu caráter de mediação que favorece o desenvolvimento do ser humano na dinâmica sociocultural do seu grupo (LIBÂNEO, 2002). Não vivemos em um mundo guiado por direitos naturais, por isso não devemos aceitar que a desigualdade e a discriminação naturalizem-se, e é nessa lógica que a difusão do conhecimento se torna uma janela, a qual mostra que mudanças são possíveis para a construção de novas perspectivas (MARTINS; CUNHA; SOSA, 2009).

A realidade sempre fora uma construção histórica decorrente da interação entre as pessoas; a compreensão, o estudo do passado, a contextualização do presente, são importantes e essenciais na elaboração de soluções frente aos problemas contemporâneos. Na falta de compreensão sobre esses fatos há forte tendência de retrocedermos nas conquistas alcançadas por longos anos de lutas.

Como a Pedagogia estuda as práticas educativas tendo em vista explicar finalidades, objetivos sociopolíticos e formas de intervenção pedagógica para a educação, o pedagógico da ação educativa se expressa na intencionalidade e no direcionamento dessa ação, já que as 
práticas educativas não estão isoladas das relações culturais, sociais, políticas e econômicas da sociedade. Como vivemos em uma "[...] sociedade em que as relações sociais baseiam-se em relações de antagonismo, em relações de exploração de uns sobre outros, a educação só pode ter cunho emancipatório, pois a humanização plena implica a transformação dessas relações" (LIBÂNEO, 2002, p. 30). Desse modo, a Pedagogia não pode deixar de se posicionar claramente sobre qual ação educativa deve tomar, sobre que tipo de cidadão/ã pretende formar.

Sendo a educação um ato político, os processos educativos precisam ser entendidos como práxis da ação cidadã, de maneira que a ação pedagógica nas instituições culturais tornem-se ações políticas. Visto que a Pedagogia integra os enfoques parciais das diversas ciências em razão de uma aproximação global e intencionalmente dirigida aos problemas educativos, os saberes dessas ciências convertem-se em saberes pedagógicos. Nesse contexto, compreende-se que,

O/A profissional da educação precisa saber muitas coisas para ensinar, mas tão importante quanto o ensino dos conteúdos, é o testemunho ético ao ensiná-los, é a preparação científica afirmando a necessidade de aliar teoria e prática, sem arrogância, com humildade e "mente aberta" para as transformações de conceitos presentes na sociedade (SILVA; MORIN; SARTURI, 2015, p. 34538).

Desse modo, o/a pedagogo/a é o/a profissional que irá atuar nos sistemas macro ou micro do ensino, sendo nas escolas professor/a, gestor/a, coordenador/a pedagógico, pesquisador/a, formador/a, e em outras instâncias educativas formador/a, consultor/a, técnico/a, orientador/a em atividades pedagógicas em empresas, órgãos públicos, movimentos sociais, meios de comunicação; na produção de filmes, nas editoras, na formação profissional; entre outros espaços. Inclusive, nas Diretrizes Curriculares Nacionais (DCN) para o Curso de Graduação em Pedagogia, licenciatura, Resolução CNE nº 1/2006 (BRASIL, 2006b), esses campos de atuação estão delimitados e explicitados de acordo com as competências do/a pedagogo/a. Portanto, como bem esclarecem Libâneo (2002) e as DCN para o Curso de Graduação em Pedagogia, a atividade profissional do/a pedagogo/a se desenvolve em um amplo leque de possibilidades frente às práticas educativas informais, não-formais e formais. 


\section{VOZES E SILÊNCIOS: VASCULHANDO ALGUNS MOVIMENTOS NO PROJETO PEDAGógICO DO CURSO DE PEDAGOGIA}

Nas últimas décadas, transformações nas práticas sociais vêm ocorrendo para atender as novas demandas da sociedade, afetando o campo investigativo da Pedagogia. Sabendo que no PPP destaca-se a intencionalidade pensada pela comunidade escolar e/ou universitária, considerando os valores, as atitudes, os discursos, as manifestações culturais e as necessidades para uma significativa educação para todos/as; no Parecer $n^{\circ}$ 5/2005, do Conselho Nacional de Educação, que trata das Diretrizes Curriculares Nacionais do Curso de Pedagogia, é previsto que o projeto pedagógico do curso de Pedagogia deverá:

[...] contemplar, fundamentalmente: a compreensão dos processos de formação humana e das lutas históricas nas quais se incluem as dos professores, por meio de movimentos sociais; a produção teórica, da organização do trabalho pedagógico; a produção e divulgação de conhecimentos na área da educação que instigue o Licenciado em Pedagogia a assumir compromisso social. Nessa perspectiva, tem que se destacar a importância desses profissionais conhecerem as políticas de educação inclusiva e compreenderem suas implicações organizacionais e pedagógicas, para a democratização da Educação Básica no país (BRASIL, 2005, grifo nosso).

Dito isso, nossa indagação sustenta-se a partir da perspectiva de reconhecer no projeto pedagógico do curso de Pedagogia Licenciatura Plena (noturno) da Universidade Federal de Santa Maria o que delineamos como sendo "vozes e silêncios dos discursos de diversidade que circulam na formação do/a pedagogo/a". Mesmo o foco sendo o PPP de Pedagogia, outros documentos foram analisados, como as Diretrizes Curriculares Nacionais do Curso de Pedagogia, o Parecer CNE/CP n 5 (BRASIL, 2005), o Parecer CNE/CP n 3 (BRASIL, 2006a) e a Resolução CNE/CP n 1 (BRASIL, 2006b). Tais documentos foram utilizados nas modificações do PPP de Licenciatura em Pedagogia (noturno) da UFSM, implantado em agosto de 2005 e reformulado em 2006 considerando a advento das Diretrizes Curriculares Nacionais do Curso de Pedagogia, de 2006.

O curso de Licenciatura em Pedagogia (noturno) historicamente apresenta um perfil de aluno/a que durante o dia trabalha e à noite estuda. "Este perfil faz com que o curso como um todo, esteja voltado para a formação de sujeitos que possuem experiências diversas no mundo 
do trabalho, alguns exercendo inclusive, a profissão de professor" (UNIVERSIDADE FEDERAL DE SANTA MARIA, 2006).

Este projeto explicita a intencionalidade de formar um/a profissional que possa atuar nas diversas realidades educacionais e possa contribuir, mesmo reconhecendo os limites de ação da educação escolar, para a transformação da sociedade, resgatando o aspecto social como fonte de reflexão, geradora de saberes. Nessa dinâmica,

Por reflexivo compreende-se a capacidade de "flexão sobre si", ou seja, a capacidade de olhar o interior de suas ações confrontando com os fundamentos e com isso, possibilitando os processos de mudanças nas práticas pedagógicas. A reflexão, por ser um ato humano, se coloca analogamente ao espelho, possibilitando a suspensão dos juízos imediatos (aparências) a fim de entrar nas causas dos fenômenos (numenom). Ou seja, a docência reflexiva, perpassa toda a formação do pedagogo e busca torná-lo capaz de integrar ação e pensamento aos fundamentos da ciência educativa. (UNIVERSIDADE FEDERAL DE SANTA MARIA, 2006).

Em análise do PPP do curso, especialmente, dos discursos dos componentes curriculares, algumas vozes e silêncios puderam ser observados. Dos 56 componentes curriculares que constituem o curso de Pedagogia Licenciatura Plena (noturno), foram localizadas 11 disciplinas que, direta ou indiretamente, continham nas ementas algo relacionado à temática da diversidade.

No componente curricular "Sociologia da Educação I" é mencionado em seus objetivos: "Possibilitar a construção de um olhar sociológico para as questões formais e não formais da educação"; imprescindíveis para a reflexão da diversidade existente na sociedade. Para isso, as unidades 2 - "Construindo e desconstruindo conceitos" e 3 - "Uma leitura dos clássicos" do programa, contemplaram tais objetivos. Nelas, foram mencionadas “[...] a perspectiva da mestiçagem [...]" e "[...] da entre-culturas"; "A Sociologia nos desdobramentos de classe social, gênero, raça, etnia e credo [...]”; “[...] a concepção da sociedade de classes [...]" e de “[...] globalização das sociedades" (UNIVERSIDADE FEDERAL DE SANTA MARIA, 2006).

No componente curricular "Sociologia da Educação II", destaca-se no objetivo o uso da linguagem não-sexista para mencionar “[...] nas diferentes possibilidades de atuação $d o(a)$ 
Pedagogo (a)", problematizando, desde já, a existência de homens e mulheres nessa área. As unidades 1 - "A sociologia do cotidiano" e 2 - "Processos de socialização: espaços educativos formais e não-formais" trouxeram assuntos relevantes para a formação do/a docente, sendo: "A observação do cotidiano", "Práticas sociais e educacionais produzidas nos espaços educativos [...]", "Processos de exclusão e inclusão sociais"; "Questões teóricas e metodológicas nas pesquisas sobre família e escola"; "Os desafios da mídia [...]" e "A violência [...]” (UNIVERSIDADE FEDERAL DE SANTA MARIA, 2006).

No componente curricular "História da Educação" destaca-se nos objetivos "Reconhecer a importância da cultura [...]" e da "[...] Educação em diversos tempos e espaços, considerando as peculiaridades sócio-históricas e antropológicas dos processos educativos". Cabe destacar nessa análise a unidade 3 - "Educação e suas concepções" e a unidade 4 - "Os movimentos históricos" que problematizam "A educação cristã primitiva"; "O pensamento pedagógico medieval"; "A influência islâmica [...]” e "A educação do outro. Índios e Jesuítas na América" (UNIVERSIDADE FEDERAL DE SANTA MARIA, 2006).

Já no componente curricular "História da Educação Brasileira", os objetivos correspondem a "Favorecer uma postura crítica [...]" e "[...] perceber a importância de estar permanentemente atualizado [...]", visto o quão importante é o papel do/a educador/a nos processos educativos (UNIVERSIDADE FEDERAL DE SANTA MARIA, 2006). Conforme o projeto pedagógico do curso,

Compreende-se por docência o processo educativo intencional tendo como referência o desenvolvimento do sujeito aprendiz em todas as suas dimensões: saber, fazer e ser. Nesse sentido, a docência, implica toda a articulação com o sistema escolar, a escola como instituição em seus processos administrativos, burocráticos, legais e de relações interpessoais. Assim, também, considera-se todos os processos pedagógicos que envolvem a comunidade escolar e o meio no qual a escola se insere. (UNIVERSIDADE FEDERAL DE SANTA MARIA, 2006).

Sabendo que a escola é um universo cultural que abrange diversos tipos humanos que convivem sob condições adversas e que carregam consigo, em suas identidades, histórias negativas de discriminação e preconceito, cabe destacar que a unidade 4 do componente curricular supracitado - “A educação Brasileira na nova República até os dias atuais (1985 em diante)" contribui para a reflexão acerca de mudanças consideráveis nas leis resultantes do movimento da democratização, após o longo período de ditadura militar (1964 - 1985). Nesse 
período, o Brasil viveu "[...] uma ferida que nos marca a todas e todos, em persistentes efeitos de regimes totalitários, autoritários, que buscam na construção da ideia de nação, de pátria, de pertencimento uma de suas mais ferozes faces de apagamento das diferenças" (AMORIM, 2010, p. 04).

Nessa esteira, no componente curricular "Políticas e Gestão das Modalidades Educativas" estão pautados nos objetivos: “[...] os movimentos sociais que originaram as políticas de educação indígena e de jovens e adultos.”, “[...] as políticas de educação especial, [...]" e a "[...] inclusão social nas ações de gestão da Educação Básica" (UNIVERSIDADE FEDERAL DE SANTA MARIA, 2006). O programa da disciplina contempla todos os objetivos citados, no entanto, não são consideradas nessa disciplina, pelo menos descritivamente, “[...] a educação na cidade e no campo; [...] a educação nos remanescentes de quilombos; a educação das relações étnico-raciais [...]”, (BRASIL, 2005, p. 04), mencionados no Parecer $n^{\circ}$ 5/2005, do Conselho Nacional de Educação, que trata das Diretrizes Curriculares Nacionais do Curso de Pedagogia.

Cabe salientar que mesmo não estando contempladas essas modalidades nem nos objetivos nem no programa, nada impede que elas tenham sido problematizadas durante o semestre. No entanto, não foi verificado no programa de disciplina do curso, tornando-se um silêncio no componente curricular do curso de Pedagogia.

As modalidades Educação de Jovens e Adultos (EJA) e Educação Especial estão contempladas em disciplinas específicas. O componente curricular "Educação de Jovens $e$ Adultos" tem por objetivos: "Interpretar as políticas públicas da modalidade [...]”; "Destacar a importância da proposta político-pedagógica [...] através da implementação do currículo da EJA” (UNIVERSIDADE FEDERAL DE SANTA MARIA, 2006).

Já o componente curricular "Educação Especial: Fundamentos" tem como objetivo "Compreender os fundamentos da educação especial no mundo e no Brasil", com destaque para a unidade 2 - "Informações básicas sobre as deficiências" e a unidade 3 - "Legislação Política", a qual problematiza os "Determinantes culturais, econômicos, políticos, ideológicos" (UNIVERSIDADE FEDERAL DE SANTA MARIA, 2006). 
No entanto, não são mencionadas quais deficiências serão trabalhadas no semestre, mas é possível ter uma breve noção com a bibliografia básica na qual são mencionadas a surdez e a deficiência mental. Dessa maneira, nem nos objetivos, nem no programa, nem na bibliografia básica são mencionadas a educação para pessoas com: transtornos globais do desenvolvimento e altas habilidades/superdotação, autismo, Síndrome de Down, cegueira, entre outras questões da Educação Especial. O componente curricular "Educação Especial: Processos de inclusão" tem seu objetivo voltado para "[...] a escola inclusiva e a sua organização" (UNIVERSIDADE FEDERAL DE SANTA MARIA, 2006).

No componente curricular "LIBRAS" os objetivos pautados são: "Adquirir conhecimento em LIBRAS", e "Proporcionar o conhecimento da Educação de Surdos e o aprendizado básico da Língua Brasileira de Sinais - LIBRAS” (UNIVERSIDADE FEDERAL DE SANTA MARIA, 2006).

No componente curricular "Contextos Educativos na Infância I" um dos objetivos busca "[...] relacionar aspectos da identidade profissional da professora e do professor da infância". Nesse componente evidenciou-se novamente a utilização da linguagem não-sexista para enfatizar a existência dos gêneros feminino e masculino na profissão de docente. $\mathrm{Na}$ unidade 2 - "A identidade profissional", é discutida a "Identidade profissional e as implicações da formação e ação pedagógica do professor e da professora [...]" pensando a “[...] carreira e as relações de gênero" (UNIVERSIDADE FEDERAL DE SANTA MARIA, 2006).

$\mathrm{Na}$ ótica das relações de gênero, Amorim (2010) salienta que a escola é repleta de conceitos, ideias que permitem a construção de significados/sentidos; sendo por meio da linguagem - palavra, imagem e som - que os indivíduos, a partir de leituras, interpretações e análises, vão construindo discursos religiosos, étnico-raciais, de gênero e de sexualidade. As atividades de ensino são campos propícios para a exploração de inúmeras identidades sociais fragmentadas que envolvem classes sociais, gênero, sexualidade, etnia, idade, crença, entre outros.

Quanto ao componente curricular "Processos da Leitura e da Escrita I", é mencionado nos objetivos "Conhecer as pesquisas e os estudos atuais sobre alfabetização e letramento". Como atualmente o índice de analfabetismo e alfabetismo funcional aumentou no Brasil, a unidade 4 - "Alfabetismo e cidadania: exclusão da e na escola" é propícia de ser trabalhada. 
Nessa unidade estão problematizadas as "Abordagens do fracasso escolar. Relações e consequências na escola [...]" e a "Educação de Jovens e Adultos" - público-alvo das taxas de analfabetismo funcional (UNIVERSIDADE FEDERAL DE SANTA MARIA, 2006).

Conforme o Parecer do CNE $n^{\circ} 5 / 2005$, acerca das Diretrizes Curriculares Nacionais do Curso de Pedagogia, no art. $5^{\circ}$, parágrafo IX, o/a licenciado/a do curso deverá identificar os problemas “[...] socioculturais e educacionais com postura investigativa, integrativa e propositiva em face de realidades complexas, com vistas a contribuir para superação de exclusões sociais, étnico-raciais, econômicas, culturais, religiosas, políticas e outras" (BRASIL, 2005, grifo nosso). Nesse contexto entra a educação, direito social de todas as pessoas, meio indispensável para a cidadania plena; determinante para que o/a cidadão/ã possa enfrentar as condições adversas da vida e do mercado de trabalho (GADOTTI, 2000).

Cabe ressaltar o papel importante das disciplinas articuladoras PED (Práticas Pedagógicas), propostas desenvolvidas nos seis primeiros semestres do curso, para estabelecer relações interdisciplinares entre todas as disciplinas trabalhadas em um semestre determinado. A PED é considerada como o ir e vir entre os saberes “[...] disciplinares, os saberes da prática educativa; entre os saberes da Universidade e os saberes da Escola, e a reflexão sobre eles, como focos importantes do trabalho a ser desencadeado neste momento da formação profissional” (UNIVERSIDADE FEDERAL DE SANTA MARIA, 2006). Essa prática pedagógica, além de possibilitar experiências compartilhadas entre docentes e acadêmicos/as, oportuniza o desencadeamento de práticas investigativas imprescindíveis na formação do/a pedagogo/a.

Compreendemos que este estudo não tem a pretensão de realizar uma crítica no sentido de apontar pontos negativos do currículo do curso de Pedagogia (noturno), mas produzir um movimento de análise e de interpretações que são pertinentes para a construção do conhecimento acerca da formação docente e, para tanto, produzir sentido para os processos de [re]estruturação curricular com o advento da RESOLUÇÃO CNE $n^{\circ} 2$, de $1^{\circ}$ de julho de 2015 (BRASIL, 2015). Consideramos que o programa de cada componente curricular torna-se flexível na medida em que o/a docente possa acrescentar ou suprimir tópicos e conteúdos que considere relevantes à formação dos/as acadêmicos/as. Todavia, acreditamos que os objetivos 
das disciplinas precisam ser problematizados e trabalhados durante o semestre, para atender minimamente os objetivos elencados pela comunidade acadêmica no PPP.

No Parecer CNE no 5/2005, que trata das Diretrizes Curriculares Nacionais do Curso de Pedagogia, no art. $5^{\circ}$, é mencionado que o/a egresso/a do curso de Pedagogia deverá estar apto/a a: “[...] X - demonstrar consciência da diversidade, respeitando as diferenças de natureza ambiental-ecológica, étnico-racial, de gêneros, faixas geracionais, classes sociais, religiões, necessidades especiais, escolhas sexuais, entre outras [...]” (BRASIL, 2005, grifo nosso). Isso implica em buscar diariamente informações atualizadas sobre tais assuntos, visto que os/as licenciados/as em Pedagogia

[...] atuarão na Educação Infantil e nos anos iniciais do Ensino Fundamental, níveis do sistema educacional que vêm abrigando maior número de pessoas com necessidades especiais, deverão ser capazes de perceber e argumentar sobre e pela qualidade da formação humana e social em escolas e organizações, incentivando para que haja a convivência do conjunto da sociedade, na sua diversidade, em todos os ambientes sociais (BRASIL, 2005, p. 13, grifo nosso).

Nesse sentido, nossa preocupação em investigar tal temática, uma vez que muitos/as pedagogos/as irão atuar em vários setores da escola e, para isso, é importante que esses/as profissionais tenham compreensão da gama de diversidade existente na conjuntura da sociedade, e construam argumentos e reflexões a favor da convivência plural e multicultural. Compreendemos que esse movimento de análise do PPP de Pedagogia Licenciatura Plena (noturno) da UFSM, possibilitou ouvir algumas vozes e silêncios em relação à diversidade.

\section{CONCLUSÕES - À GUISA DE CONTINUIDADES}

Na perspectiva de tecer algumas in/conclusões acerca desta pesquisa buscamos pautar elementos que convergem ou divergem acerca da in/exclusão na dimensão de educação para todos/as e suas inter-relações com a formação dos/as futuros/as pedagogos/as.

Não é de hoje que existem práticas de intolerância e desrespeito, guerras entre moradores, entre regiões e civilizações; esses fatos históricos são ao mesmo tempo antigos e novos. Vale lembrar que a ditadura militar no Brasil terminou faz somente 31 anos e parece que foi ontem. No entanto, muitas conquistas já foram alcançadas a partir do advento da Constituição Federal de 1988 (BRASIL, 1988), mas muito ainda precisa ser feito para 
alcançarmos uma sociedade plena de direitos e de desenvolvimento das pessoas. Para tanto, a educação é reconhecida como campo de inserção e proteção social, pois é por meio dela que poderemos construir e vivenciar essa sociedade tão almejada.

A educação como direito de todos/as, dever do Estado e da família requer ser promovida pela sociedade, e é nesse entorno que a atuação dos/as pedagogos/as, sujeitos problematizados neste trabalho, se torna significativa e de real importância. A escola e a universidade são espaços permeados por diversas vozes. Para que todas sejam ouvidas e consideradas torna-se necessária, tanto na formação inicial como na formação continuada dos/as docentes que estão atuando nas escolas, a reflexão sobre a diversidade cultural e os mecanismos de in/exclusão tão presentes na sociedade contemporânea.

Se habitamos em um universo plural de sentidos, é interessante pensarmos que dimensões da diversidade são agregadas nas culturas escolares para que curricularmente se torne possível a reflexão global e unificadora na realidade da educação (AMORIM, 2010). É nessa problematização que o PPP tem papel fundamental na construção de uma sociedade, de cidadão e cidadãs que se espera formar.

Dialogar e problematizar sobre diversidade é um processo formativo, o qual transcende a formação formal em um curso de licenciatura. Somos produzidos e produzimos na/a diversidade; somos interpelados pela necessidade de ter um olhar plural sobre nossos contextos no respeito aos cidadãos, independente de sexo, religião, etnia entre outros aspectos. Tal investigação demanda vontade de apreender e ousadia para rever nossos ideais, e é nesse aspecto que o curso de Pedagogia torna-se tão significativo, pois traz em alguns componentes curriculares temáticas voltadas para a diversidade, as quais em sua proposta original ou não abarcam a in/exclusão social de grupos discriminados historicamente por questões de gênero e sexualidade, etnia, credos/religião, deficiência, analfabetismo, representação social, classe econômica, entre outros; grupos que não podem ser marginalizados nas práticas institucionais e, portanto, educativas.

Assim sendo, tornou-se reconhecida no projeto pedagógico do curso pesquisado a produção discursiva acerca da diversidade, de maneira direta, em 11 componentes curriculares, sendo eles: História da Educação, Sociologia da Educação I e II, História da 
Educação Brasileira, Educação Especial: Fundamentos, Educação Especial: Processos de Inclusão, Políticas e Gestão das Modalidades Educativas, Contextos Educativos na Infância I, Educação de Jovens e Adultos, Processos da Leitura e da Escrita I e LIBRAS. De maneira indireta, a produção discursiva da diversidade está presente nos demais componentes curriculares, ou seja, em 45 disciplinas. Além disso, entendemos serem as disciplinas do estágio curricular supervisionado o lócus de interlocução entre o que é discutido e problematizado na academia e o que é vivido nos contextos de atuação docente, tornando-se potencializadoras de experiências com consciência político-pedagógica aos futuros profissionais da educação.

É possível afirmar que não há um componente curricular nesse curso de Pedagogia voltado para problematizar somente questões de gênero, sexualidade, étnico-raciais e de credo/religião. No entanto, esses assuntos perpassam todas as disciplinas. Não há como separar a diversidade em gavetas, ela está imbricada na sociedade, somos produtores/produzidos da/pela diversidade.

Torna-se imprescindível para a transformação da sociedade perceber e argumentar sobre/com a diversidade em casa, na escola, na universidade, em todos os ambientes sociais; incentivar a convivência no conjunto da sociedade para a qualidade da formação humana e social. Para isso, é importante também, identificar na educação informal, não-formal e formal as intenções, finalidades e interesses envoltos de propagandas, notícias, entre outras intervenções pedagógicas.

Essas questões, entre outras, que permeiam os componentes curriculares do curso são essenciais no processo formativo dos/as licenciandos/as, uma vez que oportunizam o olhar sensível e reflexivo dos/as futuros/as professores/as e, nesse sentido, o desenvolvimento do sujeito aprendiz nas dimensões do saber, fazer, ser e conviver no contexto plural e diverso das instituições educacionais e culturais. Portanto, as disciplinas que contemplam o curso e o papel dos/as formadores/as em problematizar as questões culturais e sociais inter-relacionadas ou não ao programa das disciplinas, são primordiais para que o/a egresso, futuro/a professor/a, esteja minimamente apto/a a atuar com ética e compromisso, tendo em vista sua atuação tanto macro, quanto micro, na sociedade para a construção de uma sociedade justa, equânime e igualitária. 
A diversidade cultural é decorrente de uma construção das identidades, do contexto das desigualdades e das lutas sociais. Os movimentos sociais ainda mais fortes na atualidade são vozes que ecoam em prol de uma demanda ainda pouco atendida. Para a garantia de uma educação de qualidade não se pode descartar a inclusão dos segmentos historicamente in/excluídos dos direitos sociais, culturais, econômicos e políticos (BRASIL, 2005). Respeitar não é uma questão de escolha ou opinião, é questão humana de reconhecimento do outro, entendendo-o, ou todos os outros, como diversos, múltiplos, heterogêneos e, portanto, plurais. 


\section{REFERÊNCIAS}

ALMEIDA, M. de L. P. de; TELLO, C. G. Políticas de educação escolar na América Latina: a questão da gestão em xeque!. In: BACKES, J. L.; OLIVEIRA R. T. C. de; PAVAN, R. (Org.). Políticas educacionais, currículo e diversidade cultural na educação básica. Campinas, SP: Mercado de letras, 2015, p. 25-48.

AMORIM, A. C. Diversidades culturais e escola, por linhas de combate. Anais do I Seminário Nacional: currículo em movimento. Perspectivas Atuais Belo Horizonte, Nov. de 2010. Disponível em: <http://portal.mec.gov.br/docman/dezembro-2010-pdf/7174-3-10diversidades-culturais-escola-linhascombate-a-amorim/file>. Acesso em: 09 abr. 2016.

BRASIL. Constituição da República Federativa do Brasil. Brasília, DF: Senado, 1988. Disponível em: 〈www.planalto.gov.br〉. Acesso em: 15 mar. 2013.

BRASIL. LDBEN. Lei no 9.394, de 20 de dezembro de 1996. Lei de Diretrizes e Bases da Educação Nacional. Brasília, 1996. Disponível em: 〈www.planalto.gov.br 〉. Acesso em: 18 abr. 2014.

BRASIL. Parecer CNE/CP n ${ }^{\circ}$ 5/2005. Diretrizes Curriculares Nacionais para o Curso de Pedagogia. Brasília, 2005. Disponível em: 〈http://portal.mec.gov.br $>$. Acesso em 25 jun. 2016

BRASIL. Parecer CNE/CP n ${ }^{\circ}$ 3/2006. Reexame do Parecer CNE/CP n ${ }^{\circ}$ 5/2005, que trata das Diretrizes Curriculares Nacionais para o Curso de Pedagogia. Brasília, 2006a. Disponível em: 〈http://portal.mec.gov.br〉. Acesso em 25 jun. 2016

BRASIL. Resolução CNE/CP n ${ }^{\circ}$ 1/2006. Diretrizes Curriculares Nacionais para o Curso de Graduação em Pedagogia, licenciatura. Brasília, 2006b. Disponível em:

<http://portal.mec.gov.br>. Acesso em 25 jun. 2016

BRASIL. RESOLUÇÃO CNE/CP nº 2/2015. Diretrizes Curriculares Nacionais para a formação inicial em nível superior (cursos de licenciatura, cursos de formação pedagógica para graduados e cursos de segunda licenciatura) e para a formação continuada. Brasília, 2015. Disponível em: <http://portal.mec.gov.br>. Acesso em 25 jun. 2016

BORGES, Z. N.; MEYER, D. E. Limites e possibilidades de uma ação educativa na redução da vulnerabilidade à violência e à homofobia. Ensaio: aval. pol. públ. Educ., Rio de Janeiro, v.16, n.58, p. 59-76, jan./mar. 2008. Disponível em:

<http://www.scielo.br/pdf/ensaio/v16n58/a05v1658.pdf $>$. Acesso em: 06 mai. 2015.

CASTEL, R. A dinâmica dos processos de marginalização: da vulnerabilidade a "desfiliação". Caderno CRH, n. 26. v. 10. Jan./dez., 1997. Salvador. 
CURY, C. R. J. Prefácio. In: BACKES, J. L.; OLIVEIRA R. T. C. de; PAVAN, R. (Org.). Políticas educacionais, currículo e diversidade cultural na educação básica. Campinas, SP: Mercado de letras, 2015, p. 9-12.

GADOTTI, M. Dimensão política do projeto pedagógico da escola. SEEMG. PROCAD Projeto de Capacitação de Dirigentes, Fase Escola Sagarana, Minas Gerais, 2000. Disponível em: <http://portal.iadebrasil.com.br/pos/biblioteca/alfabetizacaoletramento/moduloI/pdf/22\%20Projeto\%20Pol\%C3\%ADtico\%20Gadotti.pdf $>$. Acesso em: 14 jul. 2015.

LIBÂNEO, J. C. Pedagogia e pedagogos, para quê? 5. ed. São Paulo: Cortez, 2002.

LIBÂNEO, J. C. Organização e gestão da escola: teoria e prática. 5. ed. Goiânia: Editora Alternativa, 2004.

LIMA, M. C. Monografia: a engenharia da produção acadêmica. São Paulo: Saraiva, 2004.

LOPES, M. C.; FABRIS, E. H. Inclusão e Educação. Belo Horizonte: Autêntica Editora, 2013.

LÜDKE, M.; ANDRÉ, M. E. A. Pesquisa em educação: abordagens qualitativas. São Paulo: EPU, 1986.

LUNARDI, M. L. Inclusão/Exclusão: duas faces da mesma moeda. Revista Educação Especial, n. 18, 2001. Disponível em:

<http://periodicos.ufsm.br/educacaoespecial/article/view/5181>. Acesso em: 30 mai. 2016.

MARTINS, E. B.; CUNHA, J. L.; SOSA, D. A. A educação como aporte de socialização e constituição da cidadania: compreendendo as relações de poder como subsídio teórico na configuração dos processos educativos. Revista Publicatio UEPG Humanit. Sci., Appl. Soc. Sci., Linguist., Lett. Arts, Ponta Grossa, v. 17, n. 2, dez. 2009. p. 167-175. Disponível em: <http://www.revistas2.uepg.br/index.php/humanas/article/view/1770/1315 >. Acesso em: 30 mai. 2016.

ORLANDI, E. P. Formas do silêncio: no movimento dos sentidos. 6. ed. Campinas, SP: Editora da Unicamp, 2007.

ORLANDI, E. P. Discurso em análise: sujeito, sentido e ideologia. 2. ed. Campinas, SP: Pontes Editores, 2012.

PADILHA, P. R. Caminho para uma escola cidadã mais bela, prazerosa e aprendente. Revista Pátio, Ano VII, n. 25, p.12-15, fev./abr. 2003. 
RIO GRANDE DO SUL. Secretaria de Políticas para as mulheres. Manual para o uso não sexista da linguagem: o que bem se diz bem se entende. 2014. Disponível em:

<http://www.spm.rs.gov.br/upload/1407514791_Manual\%20para\%20uso\%20n\%C3\%A3o\%2 0sexista\%20da\%20linguagem.pdf $>$. Acesso em: 27 fev. 2016.

SANTANA, A. C.; OLIVEIRA, M. C. S. L. de. A ética da diferença: vozes e silêncio na formação de professores. In: BRANCO, A. M. C. U. de; OLIVEIRA, M. C. S. L. de. (Org.). Diversidade e cultura da paz na escola: contribuições da perspectiva sociocultural. Porto Alegre: Mediação, 2012. p. 67-93.

SILVA, C. M. Inclusão social. In: CASTRO, C. L. F.; GONTIJO, C. R. B.; AMABILE, A. E. de N. (Org.). Dicionário de Políticas Públicas. Barbacena: EdUEMG, 2012. p. 268-269.

SILVA, L. G. da; MORIN, L. P.; SARTURI, R. C. Bolsistas do PIBID/PEDAGOGIA/ANOS INICIAIS: o processo do ser docente. In: EDUCERE, XII Congresso Nacional de Educação. Anais. Curitiba/SC: PUCPR, 2015. p. 34528-34539.

STAINBACK, S.; STAINBACK, W. Inclusão: um guia para educadores. Porto Alegre: Artes Médicas Sul, 1999.

UNIVERSIDADE FEDERAL DE SANTA MARIA. Projeto Político-pedagógico do Curso de Pedagogia Licenciatura Plena Noturno. Santa Maria, RS: UFSM, 2006. Disponível em: <http://w3.ufsm.br/prograd/index.php/documentos/ppcs-projetos-pedegogicos/8-paginas/10cursos-de-graduacao $>$. Acesso em: 14 mai. 2016.

YIN, R. K. Estudo de caso: planejamento e métodos. Porto Alegre: Bookman, 2005. 